\title{
Comunidade de aprendizado na pós-graduação: cursos preparatórios em uma dialogia que nasce da solidariedade
}

Renata Nascimento da Silva

Doutoranda do Programa de Pós-Graduação em Comunicação da UERJ. Mestre em Comunicação pelo Programa de Pós-Graduação em Mídia e Cotidiano da UFF.

E-mail: renascsilva1@gmail.com

Zilda Martins Barbosa

Doutora e mestra em Comunicação e Cultura pela Escola de Comunicação da UFRJ.

Pesquisadora do Laboratório de Estudos em Comunicação Comunitária da UFRJ.

Fundadora e coordenadora do Grupo de Estudos Muniz Sodré sobre Relações Raciais.

E-mail: zildamarti@yahoo.com.br

Resumo: Este artigo propõe uma reflexão acerca das noções de educação emancipatória, de Paulo Freire, e comunidade de aprendizado, de bell hooks, a partir da ação coletiva de Cursos Preparatórios para Pós-graduação (CPP). Ademais, questiona a dificuldade de acesso de estudantes negros aos programas de mestrado e doutorado das universidades públicas, compreendidas como locus do saber de uma elite fundada no método racional da ciência e na defesa da meritocracia. As mobilizações estudantis incidem, portanto, sobre o caráter dominante das epistemologias eurocêntricas e a persistência do mérito como a principal forma de justiça social em uma sociedade desigual.
Abstract: This article aims to reflect on the notions of emancipatory education, by Paulo Freire, and learning community, by bell hooks, based on the collective action of preparatory courses for graduate students. It questions the difficulty of access of black students to master's and doctoral programs of public universities, understood as the locus of knowledge of an elite based on the rational method of science and the defense of meritocracy. Thus, student mobilizations focus on the dominant character of Eurocentric epistemologies and the persistence of merit as the main form of social justice in an unequal society. 
comunicação \& educação • Ano XXVI • número 2 • jul/dez 2021

artigo se ancora teoricamente, sobretudo, à proposta da pedagogia dialógica de Paulo Freire e ao pensamento descolonizador de bell hooks.

Palavras-chave: educação emancipatória; ações afirmativas; cursos preparatórios; comunidade de aprendizado; meritocracia.
This article is theoretically anchored to Paulo Freire's proposal of dialogical pedagogy and bell hooks' decolonizing thoughts.

Keywords: emancipatory education; affirmative action; preparatory courses; learning community; meritocracy.

\section{INTRODUÇÃO}

Este artigo pretende refletir acerca dos processos vinculados ao ensino-aprendizagem nos cursos preparatórios para a pós-graduação a partir da teoria de Paulo Freire e de bell hooks. O trabalho será desenvolvido em três tópicos. No primeiro, serão abordadas as políticas públicas de ações afirmativas e seus impactos na vivência de estudantes negros, que saem da condição de objeto de estudo para a de sujeito, tornando-se protagonistas de suas próprias vidas. Ancora-se, sobretudo, no pensamento de Paulo Freire de educação como libertação, na proposta de negritude de Aimé Césaire, em Muniz Sodré e a descolonização do processo educacional e emancipação do "monismo ocidentalista" , na rejeição do universalismo de Vergès e na crítica de Rancière ao ensino tradicional como processo dominante, construído na base da superioridade e inferioridade.

O segundo tópico versará sobre o papel dos Cursos Preparatórios para Pós-Graduação $(\mathrm{CPP})^{2}$, organizados por alunos cotistas como uma estratégia de acesso ao mestrado e ao doutorado. Serão apresentados relatos obtidos por meio de um questionário semiaberto enviado aos candidatos a fim de compreender a importância dos CPP durante o processo seletivo. Metodologicamente, foram utilizadas as técnicas de observação participante e de entrevistas, no intuito de compreender as trocas realizadas neste percurso e os processos educacionais que constituem o preparatório como um espaço de solidariedade e de questionamento acerca da estrutura eurocêntrica da universidade.

A análise se fundamenta no pensamento de bell hooks e de Paulo Freire, pois ambos criticam a educação mercantilista. Para os autores, o resultado deste modelo é o caráter patriarcalista e o racismo epistemológico dominantes. Utiliza-se também os pensamentos de Boaventura de Sousa Santos e sua reflexão em torno de uma proposta de descolonização como um incentivo à interação e à diversidade. São apresentadas entrevistas de voluntários(as) e candidatos(as) dos CPP, e são descritas as práticas de solidariedade, o compartilhamento do

1. SODRÉ, Muniz. Reinventando a educação: diversidade, descolonização e redes. Petrópolis: Vozes, 2012, p. 19.

2. Serão apresentados dados preliminares que fazem parte de uma tese de doutorado em andamento. saber e o acolhimento nesses cursos.

O último tema debaterá a origem do mérito, sua consolidação na sociedade burguesa e a violência da prática que não só individualiza e inferioriza o sujeito, mas também descaracteriza o trabalho do não espelho e seduz socialmente o indivíduo com uma retórica de merecimento pessoal. O mérito, além de retirar do Estado a responsabilidade pela oferta de condições igualitárias para todos, 
tanto materiais quanto simbólicas, naturaliza uma falácia que torna os sujeitos incapazes de perceber o ponto de partida de cada grupo social. A meritocracia é baseada na competição, mas, ao esconder a desigualdade das condições socioeconômicas dos cidadãos, perde o caráter competitivo, mantendo os iguais como vencedores. As questões apresentadas neste artigo dialogam com autores como Rousseau ${ }^{3}$, cujo mérito se tornou indispensável na construção do homem moderno, e Sandel ${ }^{4}$, para quem o mérito desorganiza as mentes dos competidores que, incapazes de perceber suas artimanhas, transformam-se em individualistas, por um lado, crentes em seu sucesso pessoal e, por outro, crentes nas escolhas inadequadas.

A dialogia de Paulo Freire está refletida na práxis de estudantes negros cotistas e na condução dos cursos preparatórios para o ingresso de mais pessoas oriundas de minorias étnico-raciais e em situação de vulnerabilidade social nos programas de mestrado e doutorado das universidades públicas. $\mathrm{O}$ artigo questiona, assim, o caráter racista das epistemologias eurocentradas e a persistência do mérito em uma sociedade desigual em vias de coexistência na diversidade. Até quando o mérito vai ser usado como um eufemismo para a manutenção da burguesia que concentra o poder dominante?

\section{AÇÕES AFIRMATIVAS: PROCESSO DIALÓGICO DIANTE DA RAZÃO INSTRUMENTAL}

As políticas públicas de ações afirmativas são o resultado das mobilizações conduzidas por movimentos negros - regionais e nacionais - pelo direito à educação e pelo reconhecimento e combate ao racismo. Na esfera política, as pressões das lideranças negras impactaram a educação do país, uma vez que o ensino nas universidades era tradicionalmente e consensualmente destinado aos brancos. Na prática, a sociedade começou a conviver com ações afirmativas e cotas raciais a partir de 2003, mas oficialmente apenas em 2012, quando essas ações foram julgadas constitucionais pelo Supremo Tribunal Federal (STF). Daí em diante, os estudantes negros saíram da condição de objeto de estudo para se tornarem sujeitos eles próprios, como afirma Joel Rufino dos Santos ${ }^{5}$. A aplicabilidade de tais políticas é afetada pelo pensamento de Paulo Freire, que compreendia a educação para a liberdade como a construção e o reconhecimento do sujeito. Diz o autor que todo seu empenho "se fixou na busca desse homem-sujeito, que necessariamente implicaria numa sociedade também sujeito" 6 .

Paulo Freire acreditava na conscientização coletiva e nas condições históricas da sociedade de implementar uma educação fundada na autorreflexão e na compreensão de seu tempo e espaço. O autor defendia a conscientização das massas de modo a tornar todos mais responsáveis, considerando uma "autorreflexão que as levará ao aprofundamento consequente de sua tomada de consciência e de que resultará sua inserção na História, não mais como espectadores, mas como figurantes e autoras" ${ }^{\prime}$. Neste aspecto, as cotas raciais representam precisamente
3. ROUSSEAU, J. - J Do contrato social. Tradução de Lourdes Santos Machado. Introduções e notas de Paul Arbousse-Bastide e Lourival Gomes Machado. São Paulo: Nova Cultural, 1999.v. 1.

4. SANDEL, Michael. A tirania do mérito: o que aconteceu com o bem comum? Tradução de Bhuvi Libanio. Rio de Janeiro: Civilização Brasileira, 2020.

5. SANTOS, Joel Rufino dos. A metamorfose do negro. In: SANTOS, Joel Rufino dos; LOPES, Nei; COSTA, Haroldo. Nação quilombo. Rio de Janeiro: ND Comunicação, 2010. P. $x x-x x$.

6. FREIRE, Paulo. Educação como prática da liberdade. Rio de Janeiro: Paz e Terra, 1983, p. 36.

7. Ibidem, p. 36. 


\section{comunicação \& educação • Ano XXVI • número 2 • jul/dez 2021}

8. CÉSAIRE, Aimé. Discurso sobreanegritude. In:MOORE, Carlos (org.). Discurso sobre a negritude. Belo Horizonte: Nandyala, 2010 p. 105-114, p. 109.

9. CÉSAIRE, Aimé. Conscience raciale et révolution sociale. L'Étudiant Noir, Paris, v. 1, n. 3, 1935, p. 2.

10. Ibidem, p. 2, tradução nossa.

11. SODRÉ, Muniz. Reinventando...Op.cit., p. 19.

12. Ibidem, p. 25.

13. VERGÈS, Françoise. Postface. In : CÉSAIRE, Aimé. Nègre je suis, nègre je resterai : entretiens avec Françoise Vergès. Paris: Albin Michel, 2005, p. 133

14. Ibidem, p. 133, tradução nossa. essa passagem da invisibilidade da ação, em uma sociedade hostil às diferenças, para o protagonismo societário, com consciência política e condições que possibilitam o sujeito a interferir criticamente no social.

O pensamento de Paulo Freire encontra similitude no de Aimé Césaire, cuja proposta é a conscientização racial como âncora para a autorrestituição do sujeito ontológico, aquele capaz de viver a "história dentro da história", restituir o sujeito para si e, consequentemente, adotar uma ação política de combate ao racismo. Foi deste processo de autorreflexão que emergiu, nos anos 1930, o conceito de negritude, cunhado pela primeira vez na revista L'Étudiant Noir e que, nas palavras do autor ${ }^{9}$, resultaria numa revolução capaz de "[...] romper a mecânica da identificação das raças, destruir os valores superficiais, inserir em nós o negro imediato, plantar nossa negritude como uma bela árvore até que ela porte os frutos mais autênticos"10.

A negritude, tal qual pensou Césaire, aparece ressignificada na potência das ações afirmativas, que consistem, de acordo com o pensamento freireano, em um poder transformador da educação como processo, ou nas sementes das árvores e nos frutos de Césaire. Considerando a diversidade cultural dos alunos que coexistem nos campi, evidencia-se o vigor da dialética nas esferas públicas dos debates, seja em coletivos, em sala de aula, em congressos ou em publicações. Contudo, não podemos afirmar que a pedagogia da esperança e o método dialógico - em que todos são sujeitos e por meio do qual se supera a oposição entre educadores e educandos, no contexto do ensino - são totalmente praticados. Os estudantes negros, uma vez na universidade, ainda se deparam com uma educação eurocentrada, e uma grade curricular cujo padrão continua sendo autores ocidentais, invisibilizando, assim, a civilização e as culturas africanas. Mesmo diante das políticas públicas e inserida na proposta de inclusão social, a práxis da universidade segue comprometida com o pensamento colonialista.

Para Muniz Sodré, em um quadro de teoria crítica da sociedade, "[...] descolonizar o processo educacional significa liberá-lo, ou emancipá-lo, do monismo ocidentalista que reduz todas as possibilidades de saber e de enunciação da verdade à dinâmica cultural de um centro, bem sintetizado na expressão "pan-Europa"'11. O autor explica o monoculturalismo pan-europeu como sendo a civilização pensada no singular. Desde modo, salta aos olhos o fato de o ensino nas universidades públicas ser ancorado em um padrão de verdade científica, o que resulta na exclusão de novos saberes, ou seja, "[...] o monismo cultural se esquiva à possibilidade de uma epistemologia pluralista"12. A justificativa, historicamente, tem sido o universalismo como princípio da igualdade.

Mas o conceito de universalismo, embora ainda seja reivindicado como parâmetro, não responde às especificidades, às subjetividades e à pluralidade do mundo. Françoise Vergès ${ }^{13}$ usa a França como exemplo, pois o país insiste no universalismo republicano e "[...] rejeita violentamente toda tentativa de 'distinguir' os grupos por sua origem étnica e cultural” ${ }^{14}$. Por outro lado, o contra discurso à hegemonia segue potente e atuante, demandando igualdade real e simbólica e, 
sobretudo, o reconhecimento histórico dos sujeitos singulares, sem discriminação. Esse combate se dá tanto na França quanto no Brasil, como observa Vergès: "Enquanto Fanon procura construir uma sociedade pós-racial, onde a cor não seja uma identificação, Césaire reivindica uma sociedade em que ser negro seja possível sem nenhuma identificação negativa associada" ${ }^{15}$.

O Brasil sofre do mal de origem. Desde a colonização, os senhores se protegiam, seja dos nativos, seja dos africanos escravizados, e o que imperava era o paternalismo, o mandonismo e o mutismo. Este, nas palavras de Freire, não era a ausência de resposta, mas a resposta sem teor crítico. Freire reconhece a dificuldade do diálogo diante de uma estrutura de domínio centrada na economia autárquica: "A dialogação implica uma mentalidade que não floresce em áreas fechadas, autarquizadas" ${ }^{16}$. A verticalização e o antidiálogo constituíam não só as estruturas sociais, mas também as instituições de ensino.

Para Rancière, a origem da discriminação está no sistema de ensino. Na obra $O$ mestre ignorante, o autor reflete acerca da emancipação intelectual, afirmando que a progressão racional do saber é uma mutilação que se repete indefinidamente. Ele critica a educação tradicional e sustenta que o papel dos explicadores está precisamente em manter um sistema, retirando a autoconfiança do aluno e perpetuando uma necessidade de mediação. "Eis a verdade dos explicadores: o ser que inferiorizaram, eles o amarram pelo mais sólido dos laços ao país do embrutecimento: a consciência de sua superioridade"17. Contudo, Rancière argumenta que essa lógica pode ser quebrada pela potência da inteligência presente em toda manifestação humana. "Não há hierarquia de capacidade intelectual. É a tomada de consciência dessa igualdade de natureza que se chama emancipação, e que abre o caminho para toda aventura no país do saber"18.

Os autores dialogam em torno da potência de ser ou de não ser do sujeito e comungam as críticas ao universalismo e as propostas de descolonização ou emancipação pela liberdade. Muniz Sodré defende uma educação local para a abertura do eu para o outro. Paulo Freire, em pensamento e ação, ressalta a necessidade de se construir uma educação com base na reinvenção do ser humano de forma radical: crítica, aberta, consciente e construtora da autonomia. A teoria do educador se sustenta na relação dialógica, participativa e comunicativa, cujos princípios "nutrem-se do amor, da humildade, da esperança, da fé, da confiança” ${ }^{19}$. Ora, é justamente a relação dialógica que sustenta e potencializa os novos intelectuais negros, que conquistaram espaço no meio universitário a partir das ações afirmativas e das cotas raciais, como sujeitos multiplicadores.

\section{CURSOS PREPARATÓRIOS: DIALOGIA PARA A DESCOLONIZAÇÃO DA EDUCAÇÃO}

A proposta de uma educação descolonizadora, nas palavras de bell hooks ${ }^{20}$, implica a construção de um pensamento crítico que questiona a mercantilização do saber e o caráter patriarcal e racista das epistemologias dominantes.
15. Ibidem, p. 97, tradução nossa.

16. FREIRE, Paulo Educação... Op. cit., p. 69.

17. RANCIÈRE, Jacques. O mestre ignorante: cinco lições sobre a emancipação intelectual. Tradução de Lílian do Valle. Belo Horizonte: Autêntica, 2007, p. 42.

18. Ibidem, p. 49.

19. FREIRE, Paulo. Educação... Op. cit., p. 107

20. HOOKS, bell. Ensinando pensamento crítico sabedoria prática. Tradução de Bhuvi Libânio. São Paulo: Elefante, 2017b. 


\section{comunicação \& educação • Ano XXVI • número 2 • jul/dez 2021}

21. $\mathrm{HOOKS}, \mathrm{b}$ ell Ensinando a transgredir: a educação como prática de liberdade. 2. ed. São Paulo: WMF Martins Fontes, 2017a, p. 29.

22. FREIRE, Paulo Pedagogia do oprimido Rio de Janeiro: Paz e Terra, 1987 , p. 39

23. HOOKS, bell. Ensinando pensamento. Op. cit., p. 43

24. SOUSA SANTOS Boaventura. O fim do império cognitivo a a firmação d a s epistemologias do sul. Belo Horizonte: Autêntica, 2019, p. 16.

25. BERNARDINO-COSTA Joaze; MALDONADO TORRES, NeIson; GROSFOGEL, Ramón (org.). Decolonialidade e pens a m e n o afrodiaspórico. Belo Horizonte: Autêntica, 2020.

26. BRASIL. Lei no 11.645 , de 10 de março de 2008. Altera a Lei n 9.394 de 20 de dezembro de 1996, modificada pela Lei ${ }^{\circ} 10.639$, de 9 de janeiro de 2003, que estabelece as diretrizes e bases da educação nacional, para incluir no currículo oficial da rede de ensino a obrigatoriedade da temática "História e Cultura Afro-Brasileira e Indígena". Diário Oficial da União: seção 1, Brasília, DF, 11 mar. 2008. Disponível em: http://www.planalto. gov.br/ccivil_03/_ato20072010/2008/lei/l11645.htm. Acesso em: 6 mai. 2021.
Neste sentido, tal política de educação se contrapõe à "educação burguesa", conforme bell hooks ${ }^{21}$, e à "educação bancária", conceito de Paulo Freire ${ }^{22}$. Segundo a autora, a estrutura educacional burguesa deprecia a noção de integridade (corpo/afeto), valoriza a cisão entre mente/afeto e corpo e impõe os valores do grupo hegemônico aos subalternizados. Já a educação bancária, na visão de Freire, representa um modelo em que o conhecimento é despejado sobre o aluno sem trocas de experiências e saberes.

Em certa medida, a educação evidencia a mercantilização do processo educacional a partir de uma lógica competitiva, cuja premissa é preparar os sujeitos para os serviços que deverão prestar às empresas e à economia. Diante desse cenário, as ações coletivas de reparação social e as atitudes de solidariedade tornam-se correções moralmente necessárias às dinâmicas sociais desiguais, tanto materiais quanto simbólicas. As políticas públicas são, assim, princípios reparadores, ideais adequados a uma sociedade em construção de um bem comum e cujos valores de vida são menos competitivos e mais generosos.

"Uma mentalidade descolonizadora" ${ }^{23}$ rompe com ideologias de dominação paternalista, racialista e subordinativa a fim de impedir que estudantes negros desacreditem que é difícil ter sucesso, entrar em uma universidade e permanecer na instituição. Boaventura de Sousa Santos dialoga com hooks ao elaborar um pensamento acerca das epistemologias do sul:

referem-se à produção e à validação de conhecimentos ancorados nas experiências de resistência de todos os grupos sociais que têm sido sistematicamente vítimas da injustiça, da opressão e da destruição causadas pelo capitalismo, pelo colonialismo e pelo patriarcado ${ }^{24}$.

Conforme defende o sociólogo português, a descolonização, além de um projeto teórico, é uma ação que desvela políticas de opressão contra negros e outros indivíduos não brancos. Ela abre espaço para que as minorias explorem seus potenciais de frequentar espaços educacionais e as incentiva a interagirem com diversos tipos de conhecimento, a partilhar experiências em sala de aula e a validar saberes ditos não científicos. De acordo com Bernardino-Costa, Maldonado-Torres e Grosfoguel ${ }^{25}$, o projeto acadêmico-político decolonial se fundamenta na capacidade de sistematizar os jogos da colonialidade do poder, do saber e do ser, a fim de criar estratégias e/ou políticas e ações que ajudem na transformação da realidade das populações afrodiaspóricas, africanas, indígenas e subdesenvolvidas.

Os autores apontam que a decolonialidade é uma ação de 500 anos, inscrita na luta da população negra e no plano de resistência de seus intelectuais, por exemplo, Lélia Gonzalez, Beatriz Nascimento, bell hooks, Abdias do Nascimento, dentre outros, bem como nos diversos movimentos negros, nos jovens cotistas e periféricos e no povo de santo. A persistência da militância negra em tornar a educação um espaço de todos pode ser exemplificada pela aprovação da Lei $\mathrm{n}^{\mathrm{o}} 11.645$, de 10 de março de $2008^{26}$, e pelas políticas de ações afirmativas, que possibilitam o acesso das minorias raciais à graduação e à pós-graduação. 
Mas é sobretudo na construção de comunidades de aprendizado, como os cursos preparatórios para o vestibular voltados a estudantes negros, e na capacitação do ingresso desses estudantes nos cursos de mestrado e doutorado que a ação político-solidário-dialógica se evidencia.

Os cursos pré-vestibulares comunitários (CPVC) são iniciativas acadêmicas que abarcam movimentos sociopolíticos de empoderamento, diversidade cultural, cidadania e ações efetivas que visam à inclusão não apenas quantitativa, mas também qualitativa de alunos negros nas universidades. Tais cursos, assegura Carvalho ${ }^{27}$, compartilham das ideias de Paulo Freire e do pensamento crítico-social, proporcionando o desenvolvimento de competências e habilidades nos estudantes para o Exame Nacional do Ensino Médio (Enem) e para os vestibulares das universidades públicas enquanto constroem a consciência crítica do universo racista que habitam.

Considerando a história de sucesso dos CPVC, estudantes cotistas de universidades públicas e de outras instituições de ensino e organizações sociais criaram os CPP com o objetivo de preparar alunos negros, indígenas, trans etc. a concorrerem a vagas em cursos de mestrado e doutorado. Em um mapeamento realizado em sites institucionais e redes sociais, em 2020 havia 68 CPP espalhados por todo o Brasil, focados nas mais diversas áreas do saber, desde Saúde Coletiva até Ciências Humanas.

De origens diversas - coletivos estudantis negros, grupos acadêmicos em prol da educação, associações de ex-alunos, instituições de ensino e organizações governamentais e não governamentais -, todos os CPP se voltam para a inclusão de minorias nos cursos de mestrado e doutorado e na afirmação das políticas de cotas nas universidades. A maioria dos CPP é administrada por alunos cotistas que estão na pós-graduação, cujo interesse é a capacitação de candidatos nos processos seletivos. Suas ações incluem a construção de projetos, o fornecimento de dicas para entrevistas, o compartilhamento de material didático e a preparação teórica para as provas. Além disso, estudantes, pesquisadores e postulantes à vagas em cursos de pós-graduação constroem relações de afeto, trocam experiências sobre a vida acadêmica, fortalecem a política de cotas e a inteligência emocional dos candidatos e estabelecem a consciência dos seus direitos diante das forças de Estado, contrárias à população negra.

No intuito de compreender a importância dos cursos preparatórios no processo da descolonização da educação, recolheram-se dados por meio de um questionário via Google Forms $^{28}$ e da observação participante. O formulário foi encaminhado para alunos de dois $\operatorname{cursos}^{29}$ preparatórios para a pós-graduação da área de Comunicação Social, contendo 21 perguntas sobre faixa etária, identificação, estado civil, graduação, opção de ingresso mestrado ou doutorado -, pontos de dificuldade na trajetória acadêmica etc.

Dentre os dados obtidos, as seguintes características foram observadas: tanto no CPP1 quanto no CPP2, a maioria dos alunos eram oriundos de universidades particulares - 63,2\% e 64,3\%, respectivamente. Ademais, 94,7\% se declararam negros no CPP1 e 92,9\% no CPP2. Em relação
27. C A R V A L H , José Carmelo Braz de. Os cursos prévestibulares comunitários e seus condicionantes pedagógicos. Cadernos de Pesquisa, São Paulo, v. 36, n. 128, p. 299-326, 2006.

28. O formulário foi enviado entre junho, julho e agosto de 2020 para os inscritos nos dois cursos preparatórios. A amostra contou com 19 respostas do CPP1 e 14 respostas do CPP2, contabilizando o total de 33 respostas.

29. Para este trabalho optamos por não utilizar os nomes dos cursos, por uma questão de privacidade das instituições de ensino e dos alunos que organizam a ação. Dessa maneira, denominamos os cursos de CPP1 e do CPP2. 


\section{comunicação \& educação • Ano XXVI • número 2 • jul/dez 2021}

ao processo de ensino, os participantes do CPP1 apontaram que o curso auxiliou na preparação do projeto, na compreensão das linhas de pesquisa e no entendimento do funcionamento da pós-graduação. Observou-se também a sensação de confiança e de segurança nascidas dos encontros entre voluntário e aluno. No CPP2, a leitura do edital, a construção do projeto e o entendimento das linhas de pesquisa surgiram empatados como pontos mais importantes. A obtenção de material didático e a sensação de segurança no processo seletivo foram o segundo e o terceiro ponto mais levantados, respectivamente.

Nota-se que a valorização dos quesitos autoconfiança e segurança estão presentes tanto no CPP1 como no CPP2, visto que os cursos acompanham os candidatos desde a primeira até a última etapa, isto é, da inscrição até a entrevista. Verifica-se que a sensação de segurança decorre do apoio dado aos candidatos pelos voluntários:

[...] eu achei muito interessante porque existia um apoio do ponto de vista acadêmico em relação aos candidatos. De olhar os projetos deles, de compartilhar os nossos pré-projetos e passar algumas dicas de escritas. No entanto, a questão central é o apoio mesmo que passamos para eles $^{30}$.

Existe um cuidado dos CPP em fornecer tanto o conteúdo da seleção como compartilhar a experiência de ser aluno cotista na pós-graduação, principalmente para aqueles que não tiveram acesso à instituição pública:

Eu fiz minha graduação toda e não sabia NADA sobre processo seletivo de mestrado, o CPP2 foi importantíssimo para eu dar os primeiros passos, me auxiliando na leitura do edital, escrita das primeiras linhas do projeto e também ajudou a entender qual melhor linha de pesquisa, o que era realmente relevante e importante no meu projeto ${ }^{31}$.

A troca de experiências entre estudantes voluntários e candidatos interessados em ingressar na universidade constitui uma cooperação que pode ser denominada comunidade de aprendizagem. Na visão de bell hooks ${ }^{32}$, comunidades de aprendizado são espaços em que os sujeitos compartilham ideias e experiências, pois entendem que todos são responsáveis pelo ato de aprender. Assim, não há fracasso. Para hooks ${ }^{33}$, pode haver afeto junto ao aprendizado, ao mesmo tempo que não se exclui a possibilidade de disputa entre os candidatos. O importante é que todas as pessoas participem e compartilhem os recursos necessários para a democratização da informação e para a construção de um pensamento crítico e empoderado.

Entende-se pelos relatos a importância da experiência acolhedora durante

30. Entrevista do candidato do curso preparatório CPP1.

31. Entrevistado candidato do curso preparatório CPP2.

32. $\mathrm{HOOKS}, \mathrm{bell}$ Ensinando pensamento.. Op. cit.

33. Ibidem preparação do candidato para o processo seletivo:

Um dos pontos foi o que mencionei sobre me sentir acolhida e integrada porque não era a única preta no curso. Eu senti em todos que deram o curso que eles não apenas apresentaram e discutiram conteúdos, eles também passaram afeto e empatia nas falas ao falarem sobre suas experiências, confessarem que também sentiram e sentiam inseguranças, mas que devíamos tentar sim o processo, porque devemos e podemos ocupar estes espaços ${ }^{34}$. 
Uma vez que os professores do curso preparatório são alunos que passaram pelo processo seletivo, formula-se uma relação dialógica horizontal, sem rigidez e hierarquia, de afetividade e de compartilhamento do saber. O domínio da técnica não é o único objeto do aprendizado; uma política de solidariedade e acolhimento voltada para a valorização do coletivo como forma de consolidação das cotas na universidade e que almeja mudanças na instituição é igualmente importante. Essas dimensões são abordadas no curso: "Para mim, foi histórico. Simplesmente pelo fato de ver pessoas iguais a mim naquele espaço. Mesmo diante de uma pandemia. Senti por alguns instantes uma nova oportunidade de realizar um sonho. Isso não teve preço algum"35.

Esse alívio externalizado pelo candidato(a) remete à quebra da expectativa social de que o espaço universitário não pertence ou não vai acolher estudantes negros. O medo do não acesso à instituição pública, da inferiorização, do silenciamento e do apagamento pode ser traduzido numa ação política de construção de comunidade de afeto e aprendizado. Segundo Audre Lorde ${ }^{36}$, a raiva e o medo podem se tornar fontes de energia a serviço do progresso e da mudança, pois se passa de uma reclamação para uma ação política. A forma como os candidatos pensam a universidade, por meio do encontro com outros estudantes negros, demostra como esses afetos podem resultar em uma política de solidariedade.

Foi muito importante um grupo de apoio emocional e sobretudo a demonstração de diversidade intelectual. Foi um projeto inteligente, estratégico que pensou de forma ampla as dificuldades de acesso ao curso de mestrado e doutorado. [...] entender que um aluno bolsista ou de escola pública provavelmente não é proficiente em inglês ou outra língua estrangeira, tem tempo reduzido para pesquisa porque necessita trabalhar desde muito jovem, a dificuldade do pagamento da taxa de inscrição $[\ldots]^{37}$

A comunhão formada no curso preparatório pode ser lida a partir da perspectiva do sistema nagô, de Muniz Sodré38, em que a coletividade gira em torno da restituição, que representa um movimento de equilíbrio e harmonia. A organização do aprendizado dos alunos segue uma lógica de reciprocidade receber e restituir - que fomenta a ideia de uma comunidade de aprendizado decolonial em que os sujeitos compartilham com os de "fora" os ensinamentos aprendidos. Para alguns participantes, os CPP são como comunidades de santos ${ }^{39}$, terreiros: "[...], tô em casa, me sentindo no ilê, no terreiro [...] estou com uma galera bacana: estou com amigos, com as amigas, com as irmãs e com os irmãos [..." ${ }^{\text {"40 }}$.

A caracterização dos cursos como ilês, feita pelo(a) candidato(a), deriva da sensação de que os indivíduos buscam assegurar a continuidade da população, o que, na contemporaneidade, decorre da educação, como aponta Sueli Carneiro ${ }^{41}$.

O pensamento nagô de Sodré ${ }^{42}$ baseia-se no axé, que representa a relação estabelecida entre sujeitos e objetos, elementos que tanto afetam quanto são afetados pela intensidade das naturezas invariáveis. Esse processo coloca o sujeito
34. Entrevista do candidato do curso preparatório CPP1.

35. Entrevista do candidato do curso preparatório CPP2.

36. LORDE, Audre. Sister outsider. New York: Crossing Press, 2007.

37. Entrevista do candidato do curso preparatório CPP2

38. SODRÉ, Muniz. Pensar nagô. Petrópolis: Vozes, 2017.

39. Ilê: casa de santos (terreiros), espaços onde pessoas de religiões de matriz africana se encontram para se fortalecer e trocar axé.

40. Entrevista do candidato do curso preparatório CPP2.

41. CARNEIRO, Aparecida Sueli. A construção do outro como nãoser como fundamento do ser. 2005. Tese (Doutorado em Educação)Universidade de São Paulo, São Paulo, 2005. 
como parte de um todo, não mais uma forma a ser separada, determinada e analisada pela lógica individual meritocrática.

Para Paulo Freire, "educação é comunicação, é diálogo, na medida em que não é a transferência de saber, mas um encontro de sujeitos interlocutores que buscam a significação dos significados" ${ }^{\text {"43 }}$. Daí a importância de entender que o processo de compreender o objeto - o ato de aprender - não acontece de modo isolado, mas em conjunto com outros sujeitos. Segundo Freire, essa troca cria uma coparticipação dos sujeitos no ato de pensar em uma comunicação verdadeira, considerando que a comunicação, tal como a educação, não se realiza na simples transferência ou transmissão do saber. É por meio do diálogo que criamos uma compreensão mais clara do significado: "O sujeito pensante não pode pensar sozinho; não pode pensar sem a coparticipação de outros sujeitos no ato de pensar sobre o objeto. Não há um "penso", mas um "pensamos". É o "pensamos" que estabelece o "penso", e não o contrário" ${ }^{4}$.

Nessa perspectiva, toma-se o sujeito ontológico não como alguém a parte do mundo, mas como indivíduo inserido nos processos históricos, culturais e sociais que se formam por meio da comunicação. Com isso, a educação ultrapassa o sentido de transferência de conteúdo de um ponto a outro e se afirma como uma reciprocidade que não pode ser rompida devido à coparticipação dos sujeitos no ato de pensar. Neste sentido, operando através da chave de leitura da comunidade de aprendizagem, de bell hooks, e em diálogo com as teorias de Freire, em que a educação é entendida como a prática de liberdade, constatou-se que os CPP são espaços de afeto, de coletividade e de construção do acesso às estruturas de poder. Esses cursos preparatórios desmantelam as lógicas de exclusão e as políticas individualizantes, criando práticas de descolonização do sistema meritocrático neoliberal que promove a competição entre os sujeitos.

\section{COMUNIDADE DE APRENDIZAGEM COMO ESTRATÉGIA CONTRA A LÓGICA DO MÉRITO INDIVIDUAL}

Os cursos preparatórios para pós-graduação, conduzidos coletivamente por estudantes cotistas, visam romper com o modelo neoliberal individualista, em que os indivíduos são treinados para alcançar o sucesso material como consequência de seu próprio esforço, dedicação e mérito. Nesse modelo, cada sujeito se torna responsável pelo seu sucesso e todos passam a ser analisados pelo mérito individual, esquecendo-se as dinâmicas desigualitárias que destroem a educação.

Michael Sandel afirma que a política neoliberal da meritocracia moderna

42. SODRÉ, Muniz. Pensar.. Op. cit.

43. FREIRE, Paulo. Extensão ou comunicação? Rio de Janeiro: Paz e Terra, 2013, p. 79.

44. Ibidem, p. 79. faz que "os vencedores" acreditem que o sucesso é fruto do seu próprio talento e empenho - mérito individual - e que "os perdedores" sintam que não aprenderam as habilidades certas para prosperar. Deste modo, o mérito faz crer que a ausência de sucesso é sinal de falta de esforço e dedicação ou de má-sorte. "A noção de que o sistema recompensa talento e empenho incentiva vencedores 
a considerar seu sucesso como resultado de suas próprias ações, uma medida da sua virtude - e a desprezar pessoas menos afortunadas do que eles" ${ }^{\prime 4}$.

Tal qual a noção propagada por Platão ${ }^{46}$, a ideia de mérito é trabalhada por este artigo no intuito de compreender sua raiz epistemológica, sua dimensão ética e seu elemento principal: a noção de liberdade pela virtude. Os princípios de liberdade também compunham a reflexão dos filósofos iluministas que impactaram a Revolução Francesa, como Jean-Jacques Rousseau, e a promulgação da Declaração dos Direitos Humanos, que orienta a sociedade desde a sua adoção pela Organização das Nações Unidas (ONU).

A concepção de meritocracia, que se origina do mérito, valor que norteia a ascensão social, decorre do processo de instrumentalização da razão na organização social. O mérito foi indispensável na (re)formulação dos homens modernos, tanto na construção da ideia de cidadania quanto na defesa da autonomia do sujeito, e o separa, classifica e categoriza de acordo com seus talentos, virtudes e realizações.

O entusiasmo manifestado no século XVIII, decorrente dos ideais iluministas e da Revolução Francesa, consolidaram alguns pressupostos, dentre eles: (1) liberdade: defesa da livre-iniciativa de comércio, presente no pensamento liberal, em oposição ao absolutismo; (2) individualismo: existência de indivíduos livres e autônomos, conscientes e capazes de autodeterminação, isto é, têm domínio da razão e esclarecimento; (3) igualdade jurídica: garantia da liberdade dos indivíduos e consolidação de uma sociedade sem privilégios, baseada no mérito e na propriedade privada.

O movimento iluminista afirmava que todos seriam iguais perante a lei, mas, ao mesmo tempo, previa a distinção entre os sujeitos. A propriedade privada era um direito natural, sagrado, inalienável e inviolável. Além disso, as profissões estavam igualmente abertas ao talento, porém se a corrida começasse em pontos desiguais, era entendido que os indivíduos deviam terminar juntos. Assim, tem-se o estabelecimento do liberalismo individualista através da propriedade privada como um direito natural, o que implica a divisão de classes, e o talento - mérito - como o meio pelo qual os cidadãos ascendem socialmente, pondo fim às distinções hereditárias.

No entanto, como ficam aqueles que começam a corrida em pontos desiguais? Segundo Littler ${ }^{47}$, a ideologia contemporânea do mérito coloca ênfase no esforço próprio, no talento individual e na competitividade. De acordo com o autor, a concepção de mérito da política neoliberal, de que se provê a política meritocrática, coloca a ideia de sucesso individualizante e competitivo como símbolo de ascensão social. De fato, a ênfase no talento individual obscurece as desigualdades do jogo social e defende o abandono de políticas de cooperação e solidariedade, principalmente no campo acadêmico de políticas educativas e sociais como os cursos preparatórios para pós-graduação e as políticas de ações afirmativas.

A política individualista, autossuficiente e competitiva da ideologia meritocrática neoliberal que chega ao século XXI, como explica Hobsbawm, tem base na
45. SANDEL, Michael. A tirania... Op. cit., p. 49. 46. PLATÃO. A república. Tradução de Enrico Corvisieri. Rio de Janeiro: Best Seller, 2002

47. LITTLER, Jo. Against meritocracy: culture, power and myths of mobility. New York: Routledge, 2017. 
48. HOBSBAWM, Eric J. A era das revoluções: Europa 1789-1848. Tradução de Maria Tereza Lopes Teixeira e Marcos Penchel. Rio de Janeiro: Paz e Terra, 1991, p. 190.

49. Ibidem, p. 137

50. BUCK-MORSS, Susan. Hegel e Haiti. Novos estudos Cebrap, São Paulo, n. 90, p. 131-171, 2011.

51. CARNEIRO, Aparecida Sueli. A construção.. Op. cit., p. 279 .
Revolução Francesa, visto que criou exames competitivos a fim de selecionar os sujeitos para bolsas de estudo em escolas burguesas. "Em certo sentido, a educação representava, tão eficazmente quanto os negócios, a competição individualista, a 'carreira aberta ao talento' e o triunfo do mérito sobre o nascimento e os parentescos, através do instrumento do exame competitivo"48.

Na observação do autor, foi o movimento francês que definiu os princípios de cidadania, as ideias universais e que, por um lado, defendeu a máxima da liberdade e da igualdade, mas, por outro, consagrou a competição individualista, as hierarquias paralelas e os sistemas burocráticos. Se a seleção por mérito se tornou um recurso para um sistema liberal, diz Hobsbawm, não representava, em contrapartida, uma política democrática ou igualitária. "E, ainda assim, os homens que exerciam os serviços públicos estavam unidos na consciência de terem sido selecionados por mérito, numa atmosfera predominante de integridade, eficiência prática e educação, e nas origens não aristocráticas"49.

Segundo Hobsbawm, o resultado da organização social por mérito foi a criação de um paradoxo, pois não se criou a "sociedade aberta" da livre competição, mas a "sociedade fechada" da burocracia e da competição que gerava uma falsa consciência educativa. Assim, a abertura da carreira ao mérito e a dedicação a educação, ao mesmo tempo que incluía algumas minorias antes excluídas da vida pública por não serem bem-nascidas -, não abarcava outros grupos sociais, como os negros.

Para Buck Morss ${ }^{50}$, enquanto os revolucionários franceses discutiam acerca da igualdade e do direito à propriedade, eles não englobavam a escravidão francesa nesse cenário. Assim, os revolucionários rompiam com a aristocracia feudal e faziam emergir uma sociedade baseada na liberdade e na igualdade jurídicas ao mesmo tempo que a França se tornava um país cada vez mais economicamente vinculado à escravidão colonial e ao tráfico negreiro. Em outras palavras, os filósofos franceses registraram a dissolução dos laços sociais entre monarquia, nobreza e igreja, atomizaram a ideia de indivíduo por meio da promulgação da Declaração dos Direitos do Homem e do Cidadão, em 1789, cujos princípios ainda ecoam na sociedade civil, mas não abordaram a questão da escravidão negra.

Tal cenário criou a máxima de que todos são iguais perante a lei e que cada cidadão é responsável pela sua trajetória individual. No entanto, esse pensamento é individual, não coletivo. Ainda, não trata das desigualdades sistemáticas que afligem grupos sociais minoritários, como a ocupação da população negra no espaço educacional. Conforme a filósofa Sueli Carneiro, a educação é o lugar em que o racismo produz mais processos de negação, ocultamento ou desvalorização da população negra. São exemplos as "[...] suspeitas veladas ou explícitas em relação à educabilidade do jovem negro, à subordinação racial que se refletem nos instrumentos didáticos e conformam a sua identidade no espaço escola" ${ }^{51}$.

Sueli Carneiro observa que tais processos começam na creche e se estendem até o sistema universitário, criando uma imagem de que os negros são inferiores e, com isso, não devem estar presentes nos espaços educacionais, e colocando 
os saberes desses grupos à margem da produção epistemológica. Neste sentido, promover políticas e ações de colaboração e solidariedade, como os cursos preparatórios para pós-graduação, permite problematizar os processos de entrada de minorias raciais no meio acadêmico e refletir sobre o processo de seleção, uma vez que alunos negros se sentem desautorizados a construir um diálogo com a banca examinadora.

Os estudantes negros também se sentem inseguros sobre sua capacidade de dominar as teorias solicitadas pelas bibliografias por enxergarem a universidade como um lugar para pessoas competentes e por não se verem desta forma. Ainda, eles têm receio de que suas pesquisas sejam vistas como militantes, sobretudo candidatos negros que pautam projetos com temáticas raciais. Isto ocorre devido ao pertencimento natural de seus corpos nessas relações e a percepção de que a lógica acadêmico-científica demanda objetividade. É certo que nem todos os espaços são desta forma e há alguns que atuam considerando a diversidade, mas estes ainda são pequenos nos centros acadêmicos.

Deste modo, os cursos preparatórios reagem às estruturas racistas por meio da criação de uma comunidade dialógica antenada com o pensamento de Paulo Freire ${ }^{52}$ e cujo empenho é a transformação constante da realidade. Em última instância, a finalidade dos cursos preparatórios é assegurar a entrada de novos estudantes negros nos programas de pós-graduação a fim de aumentar a diversidade nos centros acadêmicos do país.

\section{CONSIDERAÇÕES FINAIS}

Apoiando-se em Paulo Freire, bell hooks diz que "não podemos entrar na luta como objetos para depois nos tornarmos sujeitos" ${ }^{33}$, o que demonstra a importância de o indivíduo se apropriar do processo de aprendizagem. Segundo os autores, enquanto sujeitos programados para obter conhecimento, faz-se necessário aprender de forma consciente e a partir do diálogo, uma vez que o aprendizado demanda abertura ao próximo e engajamento na invenção e reinvenção das formas de saber. Assim, não existe um "ensinar sem aprender" ${ }^{54}$, já que o ato de aprender e de ensinar exige humildade e abertura. Para os autores, o ensinante precisa estar disponível a repensar o seu saber a partir da curiosidade dos alunos, e estes necessitam exercitar o pensamento crítico, a fim de elaborar suas próprias interpretações dos fatos. Neste sentido, Freire $^{55}$ aponta o papel fundamental dos educadores no desafio de unir a educação à construção de um mundo mais justo e democrático.

Diante das considerações de Freire, de hooks e dos demais autores apresentados neste artigo, buscou-se refletir a relevância das ações voltadas para a educação, como os CPP. Tais cursos questionam os pressupostos de uma sociedade colonialista e capitalista por meio de ações coletivas e de solidariedade entre alunos cotistas universitários, candidatos às vagas de mestrado e doutorado e a própria instituição pública, com o objetivo de compreender para mudar.
52. FREIRE, Paulo Extensão... Op. cit.

53. HOOKS, bell Ensinando pensamento.. Op. cit., p. 12.

54. FREIRE, Paulo. Carta de Paulo Freire aos professores. Revista Estudos Avançados, São Paulo, v. 15, n. 42, p. 259-268, 2001, p. 259.

55. Ibidem. 
Os CPP atuam contrários ao incentivo ao individualismo, à competição e à arrogância, frutos da sociedade capitalista que também estão presentes no sistema educacional tradicional e fizeram que a riqueza material individual fosse o principal critério de seleção e valor social, cunhados de mérito. As ações dos CPP estimulam a cooperação, a solidariedade e a construção de um bem comum no espaço educacional. Ademais, tentam quebrar a lógica do mérito individual que ignora as deficiências do Estado, visto que este não cumpre seu papel de proporcionar formação profissional igualitária, gratuita e de qualidade à população desprivilegiada socioeconomicamente, sobretudo os negros, indígenas, pessoas com deficiência $(\mathrm{PcD})$, quilombolas e demais minorias.

A pesquisa ressalta, por meio dos relatos dos candidatos e voluntários dos CPP, os movimentos de solidariedade que circulam dentro e fora das universidades públicas. Esses movimentos mostram uma aproximação destes cursos com a educação dialógica de Paulo Freire, porque estão baseadas no diálogo, na solidariedade, no afeto e na liberdade. A teoria freireana envolve a participação do educador no processo de aprendizagem, a fim de que se estabeleça o diálogo com o indivíduo sobre a condição social de alienação e passividade sob a qual ele está submetido. Dessa forma, constrói-se, junto ao educando, um aprendizado ativo que possibilita ao indivíduo superar sua circunstância de objeto e se tornar sujeito da sua história.

\section{REFERÊNCIAS BIBLIOGRÁFICAS}

BERNARDINO-COSTA, Joaze; MALDONADO-TORRES, Nelson; GROSFOGEL, Ramón (org.). Decolonialidade e pensamento afrodiaspórico. Belo Horizonte: Autêntica, 2020.

BRASIL. Lei $\mathrm{n}^{\circ} 11.645$, de 10 de março de 2008. Altera a Lei $\mathrm{n}^{\circ}$ 9.394, de 20 de dezembro de 1996, modificada pela Lei $\mathrm{n}^{\circ} 10.639$, de 9 de janeiro de 2003, que estabelece as diretrizes e bases da educação nacional, para incluir no currículo oficial da rede de ensino a obrigatoriedade da temática "História e Cultura Afro-Brasileira e Indígena". Diário Oficial da União: seção 1, Brasília, DF, 11 mar. 2008. Disponível em: http:// www.planalto.gov.br/ccivil_03/_ato2007-2010/2008/lei/111645.htm. Acesso em: 6 mai. 2021.

BUCK-MORSS, Susan. Hegel e Haiti. Novos estudos Cebrap, São Paulo, n. 90, p. 131-171, 2011.

CARNEIRO, Aparecida Sueli. A construção do outro como não-ser como fundamento do ser. 2005. Tese (Doutorado em Educação) - Universidade de São Paulo, São Paulo, 2005. 
CARVALHO, José Carmelo Braz de. Os cursos pré-vestibulares comunitários e seus condicionantes pedagógicos. Cadernos de Pesquisa, São Paulo, v. 36, n. 128, p. 299-326, 2006.

CÉSAIRE, Aimé. Conscience raciale et révolution sociale. L'Étudiant Noir, Paris, v. 1, n. 3, 1935.

CÉSAIRE, Aimé. Discurso sobre a negritude. In: MOORE, Carlos (org.). Discurso sobre a negritude. Belo Horizonte: Nandyala, 2010. p. 105-114.

FREIRE, Paulo. Carta de Paulo Freire aos professores. Revista Estudos Avançados, São Paulo, v. 15, n. 42, p. 259-268, 2001.

FREIRE, Paulo. Educação como prática da liberdade. Rio de Janeiro: Paz e Terra, 1983.

FREIRE, Paulo. Extensão ou comunicação? Rio de Janeiro: Paz e Terra, 2013.

FREIRE, Paulo. Pedagogia do oprimido. Rio de Janeiro: Paz e Terra, 1987.

HOBSBAWM, Eric J. A era das revoluções: Europa 1789-1848. Tradução de Maria Tereza Lopes Teixeira e Marcos Penchel. Rio de Janeiro: Paz e Terra, 1991.

HOOKS, bell. Ensinando a transgredir: a educação como prática de liberdade. 2. ed. São Paulo: WMF Martins Fontes, 2017a.

HOOKS, bell. Ensinando pensamento crítico: sabedoria prática. Tradução de Bhuvi Libanio. São Paulo: Elefante, 2017b.

LITTLER, Jo. Against meritocracy: culture, power, and myths of mobility. New York: Routledge, 2017.

LORDE, Audre. Sister outsider. New York: Crossing Press, 2007.

PLATÃO. A república. Tradução de Enrico Corvisieri. Rio de Janeiro: Best Seller, 2002.

RANCIÈRE, Jacques. O mestre ignorante: cinco lições sobre a emancipação intelectual. Tradução de Lílian do Valle. Belo Horizonte: Autêntica, 2007.

ROUSSEAU, J.-J. Do contrato social. Tradução de Lourdes Santos Machado. Introduções e notas de Paul Arbousse-Bastide e Lourival Gomes Machado. São Paulo: Nova Cultural, 1999. v. 1.

SANDEL, Michael. A tirania do mérito: o que aconteceu com o bem comum? Tradução de Bhuvi Libanio. Rio de Janeiro: Civilização Brasileira, 2020.

SANTOS, Joel Rufino dos. A metamorfose do negro. In: SANTOS, Joel Rufino dos; LOPES, Nei; COSTA, Haroldo. Nação quilombo. Rio de Janeiro: ND Comunicação, 2010. p. 11-58.

SODRÉ, Muniz. Pensar nagô. Petrópolis: Vozes, 2017. 
comunicação \& educação • Ano XXVI • número 2 • jul/dez 2021

SODRÉ, Muniz. Reinventando a educação: diversidade, descolonização e redes. Petrópolis: Vozes, 2012.

SOUSA SANTOS, Boaventura de. O fim do império cognitivo: a afirmação das epistemologias do sul. Belo Horizonte: Autêntica, 2019.

VERGÈS, Françoise. Postface. In: CÉSAIRE, Aimé. Nègre je suis, nègre je resterai : entretiens avec François Vergès. Paris: Albin Michel, 2005. p. 71-136. 